\title{
Descripción e intervención lingüística de la Revista de archivos, bibliotecas y museos durante el siglo XIX
}

\author{
Miguel Ángel Puche Lorenzo ${ }^{1}$ \\ Universidad de Murcia, España
}

\begin{abstract}
Resumen
La Revista de archivos, bibliotecas y museos fue una publicación periódica que, fundada en 1871, se mantuvo vigente algo más de un siglo, hasta 1979. Los números que vieron la luz en el último tercio del siglo XIX serán objeto de este estudio porque en sus páginas incorporaron las inquietudes lingüísticas de una sociedad sometida a constantes cambios, a partir de diferentes esquemas, tanto el de preguntas y respuestas establecido por El Averiguador, como el artículo que incorpora la investigación filológica o la crítica de las obras de esas características publicadas en el momento. De ellos se extraerá la forma más adecuada de estudiar la lengua, así como la consideración de determinados usos, correctos o no. Su análisis proporcionará interesantes datos para conocer las actitudes ante la lengua, su consideración social y el conocimiento interno del idioma por parte de los colaboradores. La difusión de estos hechos incidiría, sin duda alguna, en un público lector que debía desenvolverse con soltura con una de sus herramientas de trabajo: la lengua.
\end{abstract}

1 Para correspondencia, dirigirse a: Miguel Ángel Puche Lorenzo (mapuche@um.es), Departamento de Lengua Española y Lingüística General, Facultad de Letras, Universidad de Murcia, c/ Santo Cristo, 1, 30071, Murcia (España). ORCID 0000-0002-3544-6382. 
Palabras clave: historia de la lengua, prensa, siglo XIX, historia del léxico.

\title{
DESCRIPTION AND LINGUISTIC INTERVENTION OF THE REVISTA DE ARCHIVOS, BIBLIOTECAS Y MUSEOS DURING THE 19TH CENTURY
}

\begin{abstract}
The Revista de archivos, bibliotecas y museos was a periodical that, founded in 1871, remained in force for just over a century, until 1979. The issues that saw the light of day in the last third of the nineteenth century will be the object of this study because in their pages they incorporated the linguistic concerns of a society subject to constant change, based on different schemes, both the question and answer scheme established by El Averiguador, and the article that incorporates philological research or criticism of the works of these characteristics published at the time. From these, the most appropriate way to study the language will be extracted, as well as the consideration of certain correct uses, or not. Their analysis will provide interesting data to ascertain attitudes towards language, its social consideration and the internal knowledge of the language by the collaborators. The dissemination of these facts would undoubtedly have an impact on a reading public that would have to be able to deal with one of its working tools: language.
\end{abstract}

Keywords: History of the language, press, 19th century, History of the lexicon.

Recibido: 16/01/21 Aceptado: $17 / 02 / 21$

\section{INTRODUCCIÓN ${ }^{2}$}

Durante el siglo XIX se produjo la consolidación de la prensa como medio de comunicación y de difusión de conocimientos entre la sociedad. El desarrollo de este soporte escrito se vio favorecido, a grandes rasgos, porque dejó de

2 Este trabajo se ha realizado en el seno del proyecto "El léxico especializado en el español contemporáneo: 1884-1936”, PGC2018-093527-B-I00, financiado por el Ministerio de Ciencia, Innovación y Universidades. 
ser un vehículo casi exclusivo para la expresión de ideas políticas y extendió sus intereses hacia cualquier aspecto que pudiera despertar curiosidad o atención entre los diversos sectores de la sociedad. De ese modo nació el periodismo informativo y una cantidad ingente de títulos que tomaron por objeto de análisis o motivaron la divulgación de cuestiones relativas a campos temáticos concretos, como se hizo notar en la segunda mitad de esa centuria $^{3}$. Ello se vio favorecido en gran medida porque era un medio de difusión rápido y económico y, por lo tanto, accesible para la clase media y burguesa que empezaba a cobrar cierta importancia en las grandes ciudades, bajo el auspicio del nacimiento de determinados sectores industriales.

El auge y la difusión de este vehículo de comunicación novedoso, a pesar de haber nacido en siglos anteriores, provocaron que también comenzara a ser considerado desde un punto de vista teórico y, por tanto, visto como un género textual más. Con ese interés, junto a la defensa del medio en cuestión, nacieron las palabras utilizadas por Pacheco o Sellés en sus discursos de ingreso en la Real Academia Española en 1845 y 1895, respectivamente (Puche Lorenzo 2019a: 180). El propósito de describir el género en ciernes se extendió a los manuales de retórica y manuales de estilo, surgidos a finales del siglo, en los que se introdujo la descripción de los diferentes tipos textuales que podía incorporar la prensa, aunque bajo la óptica de la retórica y sin mencionar el proceso de redacción. Estas obras ofrecían diversas posibilidades a la hora de establecer tipologías textuales, en virtud de las ideologías de sus autores, así como de la propia evolución del medio (Arnaux 2019). Por ello, merece la pena destacar la perspectiva que aportó un autor cercano a los hechos como fue Ossorio (1903), quien, con denuedo, abogará por considerar a la prensa como necesidad social y como un género literario más. Aunque el medio haya recibido, antes y después, numerosas críticas y desprecios, no olvida que en sus páginas se introdujeron colaboraciones de los hombres más ilustres. Aunque se nutre de numerosas citas de autoridades como sustento de sus opiniones, se podría resaltar parte del discurso del Marqués de la Fuensanta del Valle, que manifestó lo siguiente:

El periodismo está encarnado en nuestra organización social y no es obra que la revolución ni la reacción puedan destruir; es la máquina, el procedimiento que marca la cultura y progresos que van realizándose,

\footnotetext{
La intención de este trabajo no consiste en desarrollar una historia del periodismo, por ello, para ampliar todo lo concerniente a la evolución de este medio se remite a las aportaciones de Seoane (1983), Fuentes y Fernández (1997) o Barrera (2000), entre muchos otros.
} 
institución definitiva de la sociedad, sin duda transformable, pero que no habrá fuerza bastante para hacerla desaparecer (ápud. Ossorio 1903: VII).

Los hechos expuestos se materializaron en un casi inabarcable número de publicaciones de diverso alcance geográfico (local, regional, nacional o supranacional $)^{4}$ que, gracias a la posibilidad de consulta en línea, conforman un corpus textual de gran interés para el estudio de la historia de nuestro idioma desde perspectivas novedosas y, hasta ahora, impensables. En el caso del siglo XIX, la prensa constituye una fuente de indispensable para comprender la evolución del español en un periodo que empieza a ser mejor conocido desde las diversas perspectivas del análisis gramatical ${ }^{5}$, y que se ha convertido, por tanto, en objeto de atención para los historiadores de la lengua, desvelando y aportando importantísimos datos a ese respecto ${ }^{6}$. Las perspectivas en cuanto al análisis lingüístico de este tipo de producción textual se han visto engrandecidas bajo el concepto de "textos efímeros", cuyas características se adaptan en su mayoría a las páginas de la prensa decimonónica, en el caso que aquí se abordará. Se encuentran recogidas y especificadas en Provencio Garrigós (2019: 63) y se refieren, principalmente, al tipo de mensaje, vinculado a unos hechos que se producen en un tiempo y lugar determinados y, por tanto, su vigencia o actualidad es breve, junto con una amplia variedad temática; al formato, puesto que, partiendo de una heterogeneidad formal, los textos pueden contener ilustraciones, disponer de una variada extensión y se imprimen en un material de baja calidad

4 La consulta de hemerotecas digitales arroja datos que muestran la ingente labor periodística decimonónica. Como ejemplo y partiendo solo de la prensa publicada en la Península, se puede indicar que en la Hemeroteca de la Biblioteca Nacional de España (http:// www.bne.es/es/Catalogos/HemerotecaDigital/) hay más de mil títulos digitalizados, mientras que en el portal de la Prensa Virtual Histórica (https://prensahistorica.mcu.es/es/consulta/) se localizan más de seiscientos. Habría que añadir no solo lo que otros fondos proporcionan, sino también aquellos títulos no digitalizados o perdidos en la actualidad porque tenían extensión local y se editaron durante un reducido lapso temporal.

5 Así se puede observar en las obras siguientes cuyo objeto de estudio es el español decimonónico y que lamentan, en determinadas ocasiones, el olvido que han sufrido muchos aspectos de este periodo. Véase, por ejemplo, Ramírez Luengo (2012), Zamorano Aguilar (2012), Štrbáková (2013), Buzek y Šinková (2015a y b), Melis y Flores (2015), Carpi y García Jiménez (2017) o López Serena, Del Rey Quesada y Carmona Yanes (2020).

6 Son muchos los estudios realizados a partir de la prensa de épocas pasadas, sin embargo, desde tiempos recientes y a causa de la facilidad de consulta de los fondos digitalizados son numerosos los investigadores que han tomado como objeto de investigación los textos periodísticos. Sin afán de exhaustividad, pero como ejemplo de las posibilidades que ofrecen, se puede consultar Amores y Ferrus (2017), Marimón y Santamaría (2019) o Rivas Zancarrón y Gaviño Rodríguez (2020). 
frente al libro impreso; o al espacio, porque circulan en espacios públicos o privados de la vida cotidiana y, en consecuencia, emisor o receptor pueden ser individuales o colectivos.

\section{LA PRENSA ESPECIALIZADA Y LA $R A B M^{7}$}

Tras el contexto descrito, el estudio que se desarrollará en estas páginas tendrá como objeto de análisis determinadas cuestiones lingüísticas concernientes a una publicación periódica, la $R A B M$, que se fundó en el siglo XIX y que gozó de gran prestigio entre los historiadores de la lengua. El primer número impreso vio la luz el 31 de enero de 1871 y se mantuvo vigente hasta el año 1980, es decir, fue una longeva publicación cuya vida se alargó más de un siglo. Su periodicidad comenzó siendo mensual, pero varió a lo largo de su dilatada existencia a quincenal, bimensual o trimestral. Los números aparecidos durante un mismo año conformaban un tomo o volumen, lo que permite reunir un corpus de ochenta y tres tomos que constituyen toda la producción editorial de esa publicación. El hecho de que no se superen los cien tomos se debe a que la revista contó con diferentes etapas o épocas y diversas interrupciones causadas por motivos económicos, principalmente. Por tanto, se pueden diferenciar cinco periodos, el primero se corresponde con el intervalo comprendido entre los años 1871 y 1878 y consta de ocho tomos; el segundo ocupó un solo año, 1883, y conforma un solo tomo; el tercero se refiere al periodo entre 1897 y 1931, con un total de cincuenta y dos tomos; el cuarto entre 1947 y 1953, con siete tomos; y el quinto y último periodo, abarcó los años entre 1954 y 1980, con veintidós tomos ${ }^{8}$.

Los contenidos recogidos en esta publicación periódica se corresponderán con aquellos relacionados con la formación del personal destinado en bibliotecas, archivos y museos, que eran licenciados en filosofía y letras, mayormente, o contaban con conocimientos adquiridos en la Escuela de Diplomática que se encontraba en ciernes. Pero también podían ir destinados a un lector culto próximo al mundo de la cultura en general. No obstante,

\footnotetext{
7 Mediante la sigla $R A B M$ se hará referencia a la Revista de archivos, bibliotecas y museos en el desarrollo de este trabajo.

8 El equipo de redacción estaba formado, en el momento de su fundación, por Toribio Campillo y Casamor, Mariano Andrés Domec, José María Escudero de la Peña, Antonio Rodríguez Villa y Vicente Vignau y Ballester.
} 
en la presentación del primer número se detallarán los que acogerá este nuevo recurso impreso: cuestiones relativas a la organización y servicio de Archivos, Bibliotecas y Museos, así como las disposiciones oficiales que atañen a su organización, sin olvidar las novedosas, en aquel momento, bibliotecas populares que adquirieron un importante papel en la instrucción y educación de la sociedad finisecular; trabajos originales emanados de las tres secciones del cuerpo; la publicación de documentos y datos históricos inéditos; la inserción de preguntas y respuestas formuladas por los suscriptores o individuos del cuerpo; noticias de impresos, manuscritos y objetos arqueológicos; y, por último, notas bibliográficas y anuncios de libros y periódicos ( $R A B M$ 1871: 3). Esta detallada descripción de las secciones sufrió importantes variaciones a lo largo de su dilatada vida, causada por la evolución de los intereses de la revista y del propio cuerpo de profesionales al que iba destinada.

Los contenidos recogidos en la $R A B M$ han llevado a considerarla como "el órgano más importante de expresión de la cultura española" (Magallón, Navarro y Navarro 1959: VIII), sobre todo en el periodo correspondiente al último tercio del siglo XIX y el primero del siglo $\mathrm{XX}^{9}$. Por ello, el objetivo marcado en este trabajo consistirá en el análisis de los contenidos lingüísticos aparecidos en ella y en poner de manifiesto su importancia para el mejor conocimiento de la historia de nuestro de idioma tanto desde un punto de vista descriptivo, como teórico. Sin embargo, dado que el conjunto de números publicados conforma un considerable corpus de trabajo, se ha visto la necesidad de acotarlo por la riqueza que contiene y las numerosas posibilidades que ofrece ${ }^{10}$. En estos momentos, el estudio se ceñirá a los dos

\footnotetext{
9 Una completa descripción bibliográfica de este título se puede consultar en http:// hemerotecadigital.bne.es/details.vm?q=id:0000000909\&lang=es

10 A lo largo del tiempo, en la revista se incluyeron trabajos de los más importantes maestros de la filología española como Menéndez Pelayo, Menéndez Pidal, Morel-Fatio, etc., lo que pone de manifiesto la importancia de la publicación. Por otra parte, también hay que tener en cuenta la evolución en el proceso de impresión. En un primer momento, se ocupó la Imprenta y Estereotipia de Rivadeneyra. Su director, Manuel Rivadeneyra, se había formado en establecimientos europeos y fundó su primer taller en Barcelona. Después, se trasladó a Chile desde donde impulsó la renovación del proceso de impresión en América. Allí le surgió la idea de sustituir la llamada caja antigua por la conocida como caja francesa, a pesar de que fue denominada por su inventor como caja chilena o caja Rivadeneyra y ser desconocida en tierras galas (RABM 1871: 69). Sin embargo, a partir del tercer tomo, se ocupó de este proceso la Imprenta, Estereotipia y Galvanoplastia de Aribau, en el sexto la sucedió la de T. Fortanet, en el octavo pasó a la de Enrique de la Riva. Este proceso fue continuo hasta que en el tercer periodo se creó la Tipografía de la Revista de Archivos, Bibliotecas y Museos. Bajo ese sello, se publicaron durante el primer tercio del siglo XX un gran número de obras significativas para la Filología Española, en general, y la Historia de la Lengua, en particular.
} 
primeros periodos (1871-1878 y 1883), porque son los únicos aparecidos íntegramente durante el siglo XIX ${ }^{11} \mathrm{y}$, de este modo, se posibilita una demarcación temporal coherente no solo con la revista, sino también con la propia evolución de la lengua y de las ideas lingüísticas.

Acotado, pues, el eje temporal del corpus y, en consecuencia, el número de tomos analizados, nueve en total, hay que plantear una serie de apreciaciones terminológicas que es necesario conocer para poder establecer con mayor solidez las bases de este trabajo. El propio título de la publicación elegida sugiere la primera de las cuestiones, porque se denomina revista y ello permite establecer la diferencia entre periódico y revista dentro del contexto de la prensa decimonónica. Según el DRAE (1869) ${ }^{12}$, revista es, en su cuarta acepción, "Papel periódico en forma de libro, por cuadernos, sobre materias políticas, científicas o literarias", mientras que periódico, en su segunda acepción, es "La obra ó papel que se publica en ciertos días ó por tiempo determinado. Se usa también como sustantivo en la terminación masculina"13. Este intento de diferenciación entre ambos tipos de publicaciones estaba patente durante el siglo XIX, a raíz del esfuerzo por justificar el periodismo como género literario y los subgéneros que lo componen. Desde el chileno Fidel López, en 1845, hasta Jarrín, en 1893, se encuentra latente esa intención. Este último, consciente de que las revistas están compuestas de artículos referentes a distintas materias, procede a diferenciarlas de los periódicos, como ha señalado Arnaux (2019: 14),

\footnotetext{
Desde Cantos de vida y esperanza de Rubén Darío, hasta El dialecto leonés de Menéndez Pidal (1906), pasando por otros títulos como el Estudio elemental de gramática histórica de la lengua castellana de José Alemany y Bolufer (1902), la Cartilla fonética para enseñar a los niños y sordo mudos el arte de la lectura: abecedario de Ramón Robles Rodríguez (1904), el Tratado de análisis: lengua castellana o española de Rufino Blanco y Sánchez (1925) o las Sonata de otoño y Sonata de invierno de Valle-Inclán (1905).

${ }_{11}$ El tercer periodo, aunque comienza en 1897 , se corresponde con el primer tercio del siglo XX.

12 La consulta de los diccionarios se ha realizado a partir del Nuevo Tesoro Lexicográfico de la Lengua Española de la RAE (en línea). En este caso, se utiliza la undécima edición para aportar el significado por ser la más próxima a la publicación periódica a que se refiere este estudio.

13 El cambio que experimentó el periodismo quedó reflejado en el diccionario académico, puesto que, en la duodécima edición (1884), ya se define como "Aplícase al papel que se publica periódicamente, y contiene artículo sobre política ú otras materias y noticias de varias clases". Como se puede comprobar, se desarrolla la ampliación temática que podía llegar a contener. Este proceder también se advierte en el caso de la definición de revista, dado que se introduce la definición "Publicación periódica por cuadernos, con escritos sobres varias materias, ó sobre una sola especialmente", dando cabida a una cierta "especialización”, como se atenderá a continuación.
} 
porque se dirigen a un destinatario más culto, aunque reconoce la existencia de revistas populares. Y en relación con el libro dice que las revistas "no versan sobre un solo objeto ni guardan la unidad, método y enlace, propios del organismo científico" ya que llegan a un público más amplio que el de los especialistas. Exige la competencia de los redactores en cada una de las materias que se abordan y, avizorando los requerimientos de la prensa industrial, dice que deben responder al imperativo de la actualidad para interesar a los lectores. Reconoce partes en las revistas, que implican tratamientos discursivos distintos: "una parte científica o literaria, otra bibliográfica y una tercera de variedades o crónica".

A pesar de las tentativas expuestas, una u otra denominación se utilizaban de forma indistinta durante ese periodo. Por otra parte, la $R A B M$ se podría considerar un ejemplo de prensa especializada ${ }^{14}$, sin perder de vista el entorno decimonónico. Si se realiza un paralelismo con la caracterización de las denominadas lenguas especializadas, siguiendo a Cabré (2006: 2426), se podría observar que los contenidos de la $R A B M$ están redactados por especialistas en la materia; los destinatarios esperan ser formados e informados en esa rama de conocimiento; se abordan temas de forma precisa y controlada que dominan con solvencia sus autores; se producen en una situación formal al ser un medio escrito y cuyos conocimientos no serían asequibles a gran parte de la sociedad del momento, además de estar vinculados a profesiones concretas; generalmente disponen de una función informativa y la información contenida dispone de un carácter referencial. Además del tema, existe otra serie de condicionantes a la hora de clasificar esta publicación como especializada, como puede constatarse. Todo ello, permite aseverar que es una revista especializada, aunque, el hecho de que en su interior puedan acogerse textos variados alimenta la posibilidad de que en ellos no exista el mismo grado de especialización y, por tanto, albergue artículos especializados, semiespecializados o, incluso, divulgativos, entre los que se podría establecer un continuum que daría cuenta de la forma gradual de hacer llegar esa información especializada (Rodríguez-Tapia 2016). De hecho, constituiría un claro ejemplo de comunicación profesional al disponer esta de objetivos epistemológicos y pragmáticos claramente definidos (Calvi ${ }^{8}$ 2019: 22). El símil propuesto resulta operativo para poder considerar la revista como ejemplo de prensa especializada, al margen del

\footnotetext{
$14 \mathrm{Al}$ hacer referencia a prensa especializada y haber aplicado la diferencia entre periódico y revista, no hace falta indicar que no se hace mención alguna al periodismo especializado que nació a mediados del siglo XX (Ronda Iglesia y Alcaide 2010).
} 
análisis de las lenguas de especialidad que se podrían extraer de los diversos artículos contenidos en las secciones correspondientes y que no son objeto de este trabajo.

\section{LA RABMA LOS OJOS DEL HISTORIADOR DE LA LENGUA}

Aunque la revista se divide en diversas secciones, como se ha comentado anteriormente, a continuación se procederá a presentar y analizar aquellos contenidos que resulten interesantes para el conocimiento de la lengua en el último tercio del siglo XIX. Estos asuntos pondrán de manifiesto, sobre todo, la evolución sobre el estudio lingüístico diacrónico, las actitudes ante la lengua o los avances que la disciplina había acometido durante ese periodo.

\subsection{LA RABM Y LOS DOCUMENTOS ANTIGUOS}

En los tomos que conforman el corpus, se encuentran numerosas noticias sobre el funcionamiento de bibliotecas y archivos, adquisiciones que se realizaban, ventas de bibliotecas privadas, etc. Todo un conjunto de notas que ayudan a conocer la preocupación de los profesionales de este sector para que no se perdiera el patrimonio escrito español y cuál era la situación de esas entidades. Para ello, es frecuente encontrar también entre sus páginas índices de los ejemplares que se custodiaban en esos lugares, así como proporcionar una descripción de cómo era su estado de conservación y catalogación. El abandono que sufrían los archivos, principalmente, motivó que se expresaran quejas y exigencias como la siguiente:

El decoro público y la gloria patria exigen que no perezcan interesantes documentos de nuestra historia en los dientes destructores de las alimañas, en las torpes manos de los que todo lo condenan á los más bajos usos de la vida doméstica, por estúpida ignorancia ó por nefando ahorro de algunos céntimos; y cuando se propende á que la ilustración se difunda, llevando á todos los rincones de nuestra España la luz del saber, sería vituperable, ó por lo ménos contradictorio, no evitar la destrucción de los fundamentos de nuestra verdadera historia, que han de dar á conocer mejor lo pasado, para más cabal enseñanza de los presentes y de los venideros. T. del C (RABM 31/3/1871: 38). 
Sin embargo, la dificultad que entraña esa profesión parte del acceso y la correcta comprensión de los documentos. Por ello, existe un lamento sobre el atraso que sufría la paleografía en España frente a lo que sucedía en otros países europeos, los errores que se han cometido en la transcripción de documentos y la ausencia de colecciones documentales. Además del valor histórico que estos testimonios poseen, se incide en la necesidad de realizar esta tarea con un conocimiento de la historia de la escritura, dejando entrever que la adopción de esos criterios facilitaría un estudio filológico de esos documentos, pues no se deberían introducir modernizaciones o modificaciones que alteraran el contenido:

Allanadas de esta manera las dificultades que opone la forma de las letras, deberíase ocupar de las diversas maneras de abreviar usadas en cada período, y de la ortografía y de la puntuación, necesarios complementos del estudio de los alfabetos para la exacta interpretación de los antiguos documentos. Con semejante estudio no solamente habria adquirido el alumno la preparación necesaria para el de los manuscritos originales, que podria llevar á cabo con menor trabajo del que hoy invierte, sino que atesoraría un caudal de noticias útiles que le servirían para juzgar críticamente de los diplomas. Y no son éstas únicamente las ventajas que realizaría el sistema analítico que proponemos, sino que ademas aboliría por innecesarias las alteraciones que suelen hacer por los tratadistas en el orden de las épocas paleográficas con el fin de facilitar el estudio, haciendo dificil, en cambio, que puedan apreciarse debidamente las diferentes transformaciones de la escritura de través de los siglos (RABM 31/8/1872: 250) ${ }^{15}$.

Esto se llega a expresar de forma contundente ante la transcripción de algunas colecciones documentales. De hecho, ante la edición de la Biblioteca catalana, suscita la siguiente valoración:

[...] pero al cotejar este fragmento del manuscrito con el impreso que ahora ve la luz, observamos con dolor que los editores se han permitido corregir algún tanto la ortografía del original. Comprendemos las razones que hayan podido tenerse en cuenta para hacer tal modificación, pero no podemos menos de lamentar que con este procedimiento, que

15 El texto, cuyo destacado no se encuentra en el original, está firmado por Jesús María Muñoz que fue archivero y como paleógrafo llegó a ocupar la cátedra en la Escuela Superior de Diplomática. A él se debe la publicación de diversos manuales de esta materia que gozaron de gran aceptación en el momento. Su biografía está disponible en http://dbe.rah.es/ biografias/56922/jesus-maria-munoz-rivero 
consideramos como un anacronismo y una verdadera profanación, se prive á la filología y á la lingüistica de materiales preciosos que podrían utilizarse para completar el estudio lexicográfico de los idiomas neolatinos en su doble manifestación fónica y gráfica. Ofenderíamos la ilustración de los editores, sí nos detuviéramos en comprobar la utilidad que reporta para estas ciencias, el conservar fielmente la ortografía de la antigüedad en su aparente confusion, vaguedad y falta de fijeza [...] (RABM 15/1/1874: 13).

Se podría decir que este es el momento en el que la paleografía tiende a consolidarse como ciencia auxiliar de la historia de la lengua y, de hecho, la preocupación aquí expuesta disfruta de una considerable vigencia, como ha dejado patente la redacción de unos criterios de transcripción de documentos por parte de la red CHARTA. Aunque, en este caso, partiendo de la triple edición (facsímil, paleográfica y crítica) que facilitan las ya no tan nuevas tecnologías (Sánchez-Prieto 2011). No obstante, es significativo que las pautas extraídas de la $R A B M$ indiquen la necesidad de contar con formación filológica a la hora de abordar los textos antiguos, en la línea de las numerosas opiniones vertidas al respecto por Menéndez Pelayo para quien el acceso a un manuscrito partía del conocimiento de la paleografía, pero sobre todo de la lengua, lo que le llevó a oponer, con cierto desdén, los oficios de paleógrafo y filólogo.

El interés por la antigua documentación española, independientemente de la lengua en que estuviera redactada, condicionó que una parte considerable de la $R A B M$ se destinara a la publicación de fondos de archivo, hasta ese momento desconocidos, que facilitaran el mejor conocimiento de la historia de España desde cualquiera de sus facetas ${ }^{16}$. El motivo que se perseguía era la creación de una colección de documentos para la historia de España que siguiera los preceptos de las que se habían hecho ya en Francia u otros países europeos. Aunque se contaba con ediciones publicadas con anterioridad,

16 Los textos publicados son tanto literarios como no literarios, aunque se le da especial preponderancia a los no literarios por la importante información que aportan. A esta labor colaboraron Morel-Fatio (RABM 5/6/1876: 195), Amador de los Ríos (RABM 20/10/1876: 335) o Milá y Fontanals (RABM 5/11/1876: 345). A veces, se deja constancia de la relevancia que tiene un documento concreto para la filología porque atañe a una minoría étnica o religiosa, como fue la judía. Un ejemplo de ello se observa a continuación: "Del interesante Becerro de Aguilar de Campó, que se custodia en el Archivo Histórico Nacional, tomamos el siguiente documento, importantísimo bajo el punto de vista filológico y que da á conocer el carácter del romance castellano hablado por los judíos de España” (RABM 31/7/1871: 170). 
estas no reunían unos criterios paleográficos serios ni respetaban la lengua originaria del documento. Antonio Rodríguez Villa ${ }^{17}$ lo manifestó así:

La primera y más urgente medida que en el estado de oscuridad y confusión en que hoy se encuentra, requiere la historia de España, si ha de ser realmente útil á los pueblos y á los individuos, y satisfacer las condiciones impuestas por la Crítica y la Filosofía, es, á no dudarlo, la publicación de una colección general, metódica y razonada, de documentos, que sirva á la par de base y de comprobante á la historia patria (RABM 31/10/1872: 309).

Desde el punto de vista lingüístico, la edición de documentos adquiere un valor superior porque se hacían acompañar de numerosas notas referentes al léxico que contenían y cuyo desconocimiento podría dificultar la lectura. En diversos textos así se actúa, aunque no sea un proceder regular. En el caso del inventario del duque de Calabria, publicado por partes en los ocho primeros números correspondientes al año 1871, se explican voces como maslo, mantí, guaspa o rovejado, que no se habían recogido en ningún diccionario, quizás por ser términos catalanes o valencianos castellanizados. Mientras que otros como escarpe o estradiota, sí habían sido introducidos en algún diccionario ${ }^{18}$, pero podrían parecer oscuros a los ojos del lector del momento. No se incidirá más en estas cuestiones dado que serán abordadas con detenimiento en el próximo apartado.

\subsection{PREguntaS y RESPUESTAS EN LA RABM}

Se ha considerado que una de las partes más valiosas de la primera etapa de esta revista fue la concerniente a los juicios y a la documentación de vocablos $\operatorname{antiguos}^{19}$. Aunque estos aspectos podrían derivarse de las anotaciones a

17 Con posterioridad a este escrito publicó numerosos estudios acompañados de apéndices documentales inéditos en los que intentaba cumplir con la seriedad en la presentación que en este artículo anunciaba. Así mismo, colaboró con Gayangos en la realización de un catálogo de manuscritos españoles conservados en el Museo Británico. De todo ello, fue dejando cuenta en la $R A B M$.

18 Escarpe aparece por primera vez en el suplemento al diccionario de la editorial Gaspar y Roig (1953: s.v. escarpe) y posteriormente se recogería en DRAE 1925 (s.v. escarpe). Sin embargo, la definición de estradiota fue copiada casi literalmente de la contenida en el diccionario académico desde Autoridades (s.v. estradiota).

19 Véase lo contenido en http://hemerotecadigital.bne.es/details. $\mathrm{vm}$ ?q=id:0000000909\&lang=es. La información de la web parece haberse extraído de la 
pie de página, existe una sección de la revista destinada a la realización de preguntas y respuestas donde se abordarán estas y otras cuestiones, principalmente referidas a usos lingüísticos, y en menor medida a otras curiosidades de carácter histórico, como se especifica en los propósitos iniciales que persigue la revista: "Daremos también lugar á la publicación de documentos y datos históricos inéditos, á la de preguntas hechas por los suscritores ó individuos del Cuerpo, relativas á asuntos de su instituto, y á las respuestas que á las mismas se dieren" (RABM 31//1871:3). La estructura de preguntas y respuestas había dado lugar, a mediados del siglo XIX, al nacimiento en Europa de un tipo de publicación periódica que provocó que en España surgieran El Consultor Universal (1865) en Barcelona y El Averiguador (1867) ${ }^{20}$ en Madrid. La vida de estos títulos fue corta y plagada de intermitencias y refundaciones ${ }^{21}$, aunque el modelo de interacción con el lector que implicaba se transmitió a muchos periódicos del momento que llegaron a denominar a esa sección concreta como "El averiguador" (Puche Lorenzo en prensa).

Este proceso dialógico que se estableció en las páginas de la $R A B M$ podía ser objeto de arduos debates sobre algún asunto concreto, pues una pregunta podía recibir más de una respuesta y que generase una polémica, más o menos agria, entre los que contestaban. En otras ocasiones, sin embargo, esas preguntas no encontraron quien las respondiera. De este complejo interactivo, raras veces conocemos a los autores que en él participaban porque era habitual que sus aportaciones fueran firmadas mediante seudónimos o

publicación de los índices de la revista en 1959, donde se lee "La sección titulada 'Preguntas y respuestas', en la que sus autores exponen sus opiniones documentadas y atinados juicios sobre vocablos y frases empleadas en los documentos medievales o sobre puntos de arqueología, bibliografía, artes e historia, es, a nuestro juicio, lo mejor de esta primera época, ya que las tesis sostenidas han sido de gran utilidad para la formación de las futuras generaciones de archiveros, bibliotecarios y arqueólogos" (Magallón, Navarro y Navarro 1959: IX).

20 A este periódico dedicó Sbarbi (1891: 72-73) una reseña en la que indicó que este género de lectura tuvo su inicio en España "en Barcelona, con el título de El Consultor Universal". Se lamentaba de la falta de longevidad de estas revistas, pero señalaba que "mi afición decidida á semejante linaje de estudios, fue móvil poderoso para arrastrarme á la prosecución de $E l$ Averiguador". En relación con el primer título mencionado y ante la aparición de preguntas y respuestas en otros periódicos, el 2 de febrero de 1876 se le planteó a El Averiguador si "¿Existen ó han existido en España algunos otros periódicos que las inserten ó hayan insertado?", a lo que se respondió, en diciembre de ese mismo año "Tengo en mi poder una hoja de El Consultor Universal, comprensiva de las páginas 5 y 6 del núm. 1, correspondiente al dia 25 de Enero de 1865. Puedo añadir que se publicaba en Barcelona, sin otros detalles".

${ }^{21}$ En el caso de El Averiguador así sucedió. Tras una intermitente vida, desapareció en 1876 y fue refundado, en 1879, bajo el título de El Averiguador Universal (Provencio Garrigós en prensa). 
abreviaturas. Lo que no cabe duda es del valor filológico que tuvieron en su momento, pues las argumentaciones publicadas fueron recopiladas por el Conde de la Viñaza (1893), así como del estrecho vínculo que existió entre El Averiguador y la $R A B M$, como se desprende de la siguiente nota ${ }^{22}$ :

Ha vuelto á aparecer El Averiguador, correspondencia entre curiosos, literatos anticuarios, etc., etc., estimable periódico, del que se publicaron 22 números desde Diciembre de 1867 hasta Mayo de 1868, y que ademas de prestar no escasos servicios con el esclarecimiento ó noticia de cuestiones literarias de todo género, inserta curiosísimos documentos, relativos principalmente á la Historia de las artes, y bajo el epígrafe de Movimiento bibliográfico da noticia de los libros que sus suscritores desean adquirir, cambiar ó vender. Recomendamos vivamente á los individuos del Cuerpo, en sus tres secciones, esta publicación, hermana de la nuestra, y cuya redacción en Madrid está en la calle de Atocha, núm. 143, principal (RABM 31/1/1871: 10 ${ }^{23}$.

El contenido y estructuras similares llevan a considerar que este periódico fue el germen de la $R A B M$, aunque, con el paso de los años, esta fuera incorporando contenidos más especializados, lo que le procuró una longeva vida. De hecho, la sección de preguntas y respuestas estuvo presente en la $R A B M$ hasta 1878 . Después se eliminó de la estructura de la revista. Ello se explicaría porque también desapareció El Averiguador y, aunque se refundó en 1879 bajo el título de El Averiguador Universal, este hecho coincidió

22 Debieron de ser dependientes porque en la relación de la correspondencia particular recibida se deja testimonio de la suscripción recibida para El Averiguador (RABM 28/2/1871: 32). Como muestra de lo indicado, se deja patente que determinadas preguntas proceden de aquel periódico introduciendo, entre paréntesis, el título (De El Averiguador), como sucede en la pregunta sobre trompetas bastardas ( $R A B M$ 15/4/1871: 62). Otras veces, se comparten polémicas y discusiones: "En uno de los útimos números de El Averiguador apareció un suelto preguntando el significado de las palabras que sirven de epígrafe á este artículo [Citi, Velliti], y que en los siglos X, XI y XII se hallan frecuentemente entre los testigos enumerados en nuestros documentos. No se hizo esperar mucho la respuesta; dos se publicaron consecutivamente [...] Nótase en ambas falta de textos que apoyen las opiniones de sus autores, quienes o citan ninguno, ó por evitarse la molestia de manejar añejos pergaminos, ó por no poner en ellos trabas á su imaginación, ávida de correr sin freno por el aventurado campo de las elucubraciones etimológicas" (RABM 30/4/1871: 74).

23 La declaración de intenciones también se expresa al final del primer número publicado. Como era de esperar, aparecen preguntas, pero no respuestas y en ese apartado los redactores dejan patente cuál será su proceder: "Desde el próximo número insertarémos las que se nos remitan, tanto á las preguntas hechas en nuestro periódico, como á las de nuestro apreciable colega El Averiguador" (RABM 31/1/1871: 16). 
con la intermitencia que tuvo la revista entre el primer y segundo periodo, momento este, 1879-1882, en el que dejó de publicarse.

En cuanto al contenido de esta sección, las preguntas que se plantean están orientadas, sobre todo, a resolver las dudas que genera la ortografía, la etimología y el significado de las palabras o la consideración de sinónimos o no.

\subsubsection{Aspectos ortográficos}

La consulta de documentos redactados en épocas pasadas suscita en el lector, por un lado, determinadas dudas acerca de cómo deben escribirse determinadas palabras, al existir en nuestra lengua ciertos fonemas dígrafos $\mathrm{y}$, por otro, interés sobre el origen de ciertas diferencias gráficas que tiene el español frente a otras lenguas románicas:

\section{Preguntas}

144. U y V.- ¿Cuándo empiezan á distinguirse entre sí estas dos letras, en la escritura? V.C.S. (RABM 15/7/72: 210).

287. Ortografía de la $\boldsymbol{j}$ y de la $\boldsymbol{g}$.- ¿Tiene la lengua castellana reglas fijas para establecer de una manera precisa y razonada cuál de estas dos letras debe usarse en aquellas sílabas en que tienen ambas un mismo sonido? ¿Podrá, por ejemplo, decírsenos con arreglo á ellas, por qué la palabra jefe debe escribirse con j, y si la palabra mujer debe escribirse con $j$ ó con $g$, pues con una y otra letra la vemos escrita? (RABM 31/1/74: 30 $)^{24}$.

52. N.- ¿Cuál es el origen de la figura y del sonido de esta letra, peculiar de nuestro idioma? O. $(R A B M 15 / 8 / 1871: 188)^{25}$.

24 En esta ocasión, fueron dos las respuestas publicadas, en 28 de febrero, pp. 61-63, y 30 de marzo de 1874 , p. 95, respectivamente, de gran extensión, en las que se recurría al origen etimológico de las palabras para conseguir dictaminar si debían utilizar una u otra grafía. Solo se reproduce la segunda como ejemplo ilustrativo. En ellas queda demostrado el conocimiento de la evolución de los fonemas palatales. En la primera se menciona la falta de correspondencia entre pronunciación y escritura, a pesar de que sea ese un criterio ideal, y se plante el origen árabe e la pronunciación de la $j$. A través de esa respuesta, se deduce el conocimiento de las leyes fonéticas, descubiertas por Schlegel y Rask, aunque formuladas por Grimm, a partir de las que se muestra lo innecesario de recurrir al origen árabe para el sonido de la $j$. La referencia al origen de este resultado fonético recuerda al comentario que casi un siglo después redactó Menéndez Pidal (1961: 21) al indicar que "creo en el celtismo de la $\ddot{u}$, como en el iberismo de la $f$, pero no creo por ahora en el arabismo de la $j$ ".

25 La respuesta corrió a cargo de J. M. E. de la P. (José María Escudero de la Peña) que formaba parte del equipo de redacción de la revista y fue un asiduo colaborador de $E l$ 


\section{Respuestas}

Entre los romanos predominó el uso de la V para designar la vocal y la consonante; durante la Edad Media aconteció lo mismo en la escritura capital, pero en la minúscula fue la $u$ exclusivamente usada hasta el siglo XI, y con preferencia sobre la $v$ en los que siguieron. La distincion de estas dos letras, vocal y consonante, no se fijó en la escritura ántes de los fines del siglo XVII. M. y R. (RABM 15/8/1872: $243)^{26}$.

Mujer debe escribirse con $j$ y no con $g$, siguiendo la analogía de todas las palabras de origen latino en que juega la $l$ entre dos ó más vocales, de las cuales la segunda es $i$, como alienum=ajeno; alium=ajo; [...] La regla que parece haber seguido la lengua castellana para el uso de la $x, g$ y $j$ en las voces en que estas tres letras tienen el mismo sonido, es el origen de la palabra [...] las muchísimas excepciones que tiene son hijas del uso y de la ignorancia de los escritores, pues éstos, como los que hablan, unos saben lo que dicen; otros saben lo que saben. A. M. G. B. (RABM 30/3/1874: 94).

Esencialmente paleográfico es el origen de la ñ, llamada también $n$-tilde por la tilde ó signo de abreviación paleográfica, que denotaba en la escritura de las edades antigua y media la supresión de una $n$ en ciertos vocablos que llevaban dos. Ya á fines del siglo XV decia nuestro Antonio de Nebrija: "La ch, la ll y la ñ son letras propias nuestras"; por cierto que entre éstas no incluia la $j$ con el sonido fuerte que hoy día tiene. Por lo que del manejo de los documentos puede colegirse, en la segunda mitad de ese mismo siglo xv fué cuando la ñ comenzó á tener el valor independiente y el sonido que hoy le damos [...] (RABM 31/8/1871: 208).

Las preguntas que se adjuntan muestran cómo se ven alentadas tanto por la curiosidad de conocer el pasado del idioma, en su faceta gráfica, como por un criterio de corrección ortográfica. Ante eso, los redactores de las respuestas son fieles seguidores de la norma, representada por las obras académicas, que en la ortografía seguía un criterio etimológico desde que así quedara plasmado en el proemio del Diccionario de Autoridades. Por ese motivo, se vierten criterios y opiniones despectivas (véase la secuencia en negrita del cuadro) como ejemplo de una actitud y una ideología relacionadas con esa norma de corrección, pero también de centralización, como se verá en otros

Averiguador (Puche Lorenzo en prensa). Acierta al considerar el origen de esta grafía en un proceso de abreviación y que el sonido, procedente de grupos consonánticos latinos, es compartido por el resto de lenguas románicas. Sin embargo, yerra al pensar que el sonido actual se generó en el siglo XV.

26 Hay que pensar que, efectivamente, en situación inicial se mantuvo el uso de la v con valor vocálico, criterio que se debía a una cuestión más estética y de ornato que gráfica, como manifestó Juan de Valdés (Esteve Serrano 1982:134). 
casos, pues las aportaciones de las respuestas coinciden con los presupuestos académicos encaminados, de forma compartida, a realizar un buen uso de la lengua (Martínez Egido 2019: 177).

\subsubsection{Sobre el origen y el significado de las palabras}

El trabajo como archivero o bibliotecario llevaba aparejado la consulta de textos antiguos, redactados en las diferentes etapas de la evolución de la lengua. El acceso a ellos, a su correcta compresión y lectura, y la posibilidad de editarlos de la manera más adecuada implicaba tener un conocimiento correcto de las palabras que se desplazaban en su interior y que, a menudo, en numerosas ediciones coetáneas estaban mal transcritas, fenómeno que desvirtuaba el contenido e impedía su interpretación. El interés por el documento antiguo que facilitaba el acceso a un mejor conocimiento del pasado estaba en consonancia con el historicismo de ese periodo. Este hecho se encuentra vinculado con el propio desarrollo que la ciencia filológica experimentó en el siglo XIX, especialmente preocupada por el modelo comparativo y, en consecuencia, por el origen de las lenguas. Este entorno propició una mirada hacia las variedades lingüísticas regionales y nacionales, las historias de palabras o la etimología. A raíz de ello, se publicaron diccionarios etimológicos haciéndose eco de esa corriente europea (Puche Lorenzo 2002; Carriazo Ruiz 2017), de hecho, la propia Academia, que había suprimido esa información en la primera edición del DRAE para hacerlo más manejable y asequible, volvió a introducirla a partir de la duodécima edición (1884) (Alvar Ezquerra 1983: 213).

El conjunto de circunstancias descritas propició que se recogieran en la revista unas doscientas preguntas sobre el origen, la etimología o el significado que tenían determinadas voces. A causa de estar incluidas en documentos medievales y no estar recogidas en los diccionarios generales del momento, se plantean preguntas del tipo:

\begin{tabular}{|c|c|}
\hline Preguntas & Respuestas \\
\hline $\begin{array}{l}\text { 2. Caçmí. -En un documento del año } \\
1105 \text { y en otros de época posterior } \\
\text { se encuentra la frase argento caçmí, } \\
\text { cuya significación se ignora por no } \\
\text { encontrarse en ninguno de los glosarios } \\
\text { más conocidos. ¿Es de origen árabe ó } \\
\text { hebreo esta palabra? ¿Qué significa? } \\
(R A B M 31 / 1 / 1871) \text {. }\end{array}$ & $\begin{array}{l}\text { 1. Llamábanse doblas cacemies á las } \\
\text { acuñadas primeramente por Caçmín, } \\
\text { prefecto de la Ceca [...] de modo que } \\
\text { entendemos que argento caçmí vale } \\
\text { tanto como moneda acuñada con arreglo } \\
\text { á la ley de las doblas caçemíes. G. } \\
\text { 2. Es de origen hebreo [...] de modo que } \\
\text { plata caçmí era plata pura, ó plata capaz } \\
\text { de dársele al mejor alquimista. A. M. G. } \\
\text { B. (RABM 28/2/1871). }\end{array}$ \\
\hline
\end{tabular}




\begin{tabular}{|c|c|}
\hline $\begin{array}{l}\text { 243. Maridaraque.-En documentos } \\
\text { castellanos del siglo XIII se lee: } \\
\text { "fareedes me vos maridaraque". Se } \\
\text { desea saber el significado de esta voz } \\
(R A B M 15 / 10 / 1873)^{27} \text {. }\end{array}$ & Sin respuesta. \\
\hline $\begin{array}{l}\text { 340. Frixideras.- En un inventario del } \\
\text { siglo XVI se encuentran, entre otros } \\
\text { objetos, "Dos frixideras de plata con } \\
\text { sus asas, de peso de siete marcos". } \\
\text { ¿Qué quiere decir la palabra que va } \\
\text { subrayada? (RABM 30/4/1874). }\end{array}$ & $\begin{array}{l}\text { Indudablemente del latin frigidare, } \\
\text { enfriar, y debe ser una cacerola ó } \\
\text { jarro para hacer helados, ó mejor para } \\
\text { servirlos a la mesa, teniendo en cuenta } \\
\text { que eran de plata las que se mencionan en } \\
\text { el inventario citado ( } R A B M 31 / 5 / 1871) \text {. }\end{array}$ \\
\hline
\end{tabular}

Los ejemplos adjuntos muestran tres tendencias en la $R A B M$ a la hora de abordar la etimología. La primera se refiere a la discusión etimológica que motiva la publicación de más de una respuesta con propuestas diferentes. En este caso, se orienta al origen árabe o hebreo de algunas voces, pues la tendencia purista tendía a restar importancia a la presencia árabe en la configuración del léxico español. Aunque a este motivo, se unía el hecho de buscar un origen más lejano en el tiempo para esas palabras fruto del historicismo del periodo. Los otros dos ejemplos representan, por un lado, la ausencia de interés por el vocablo, aunque se desconoce si las intermitencias en la publicación pudieron contribuir a ello, y, por otro, la reconstrucción etimológica. Lo que sí quedó suficientemente demostrado es que la incorporación de estos contenidos repercutió en publicaciones posteriores, pues, al no disponer de refrendo lexicográfico, se recurrió a estas aportaciones léxico-semánticas a la hora de confeccionar determinados glosarios ${ }^{28}$.

En otras ocasiones, las dudas que suscita el léxico de los documentos se originan en el hecho de pertenecer a zonas geográficas diferenciadas lingüísticamente en el pasado o el presente. Aunque se encuentran ejemplos variados, existe una preponderancia de aquellas voces que poseían filiación aragonesa ${ }^{29}$ :

27 La circunstancia de no publicar una respuesta será frecuente en los últimos números del primer periodo, entre 1874 y 1878 .

28 Así se ha podido constatar en el editado por Vignau, Glosario y Diccionario geográfico de los documentos del monasterio de Sahagún publicado en 1874 en la Imprenta, Estereotipia y Galvanoplastia de Aribau. En él se recoge, por ejemplo, la doble propuesta de caçmí publicada en la $R A B M$, casi literalmente.

29 Los regionalismos y las expresiones dialectales hallaron su centro de propagación también desde las páginas de la prensa como se ha podido ver en el caso del andaluz (Bastardín 2020) o del murciano (Abad Merino en prensa). Perteneciente a este último, se encuentra 


\begin{tabular}{|c|c|}
\hline Preguntas & Respuestas \\
\hline $\begin{array}{l}\text { 238. Sargantana.-¿Cuál es la } \\
\text { etimología de esta voz con que en } \\
\text { Aragon hemos oído designar á la } \\
\text { lagartija? (RABM } 15 / 9 / 1873) \text {. }\end{array}$ & $\begin{array}{l}\text { Encontramos, con efecto, la voz sargantana } \\
\text { en el Diccionario de voces aragonesas, por } \\
\text { D. Jerónimo Borao, que no dice más sino } \\
\text { que equivale á lagartija [...] Ja voz sarga, } \\
\text { ademas de á una tela de seda, se aplica, } \\
\text { según el Diccionario de la Academia (que } \\
\text { omite, digámoslo de paso, sargantana) } \\
{[\ldots](R A B M 30 / 9 / 1873)^{30} \text {. }}\end{array}$ \\
\hline $\begin{array}{l}\text { 448. Aliva. En el país de los } \\
\text { Maragatos se designa con este } \\
\text { nombre un utensilio de labranza: } \\
\text { ¿cuál es éste? ¿cuál es la etimologia } \\
\text { de esa voz? (RABM 20/3/1875). }\end{array}$ & Sin respuesta. \\
\hline $\begin{array}{l}\text { 451.Gurriato.-En Carvajales, } \\
\text { partido de Alcañices, se designa } \\
\text { así al cerdo; en la Mancha se le } \\
\text { llama gorrino; en Castilla la Nueva, } \\
\text { guarro. Esta voz onomatopéyica, } \\
\text { que parece la primitiva de las dos } \\
\text { primeras, ¿qué orígen tiene? ¿El } \\
\text { adjetivo gordo no entrará en el grupo } \\
\text { genealógico de los derivados de } \\
\text { la raíz de dicho nombre? (RABM } \\
\text { 5/4/1875). }\end{array}$ & Sin respuesta. \\
\hline
\end{tabular}

El análisis y contextualización de los casos expuestos permiten adentrarse en la doble actitud existente ante la lengua, reflejada en el léxico en esta ocasión, a partir de los redactores y lectores de la revista. La pregunta efectuada por el lector se preocupa por la variedad dialectal, mientras que el redactor, representaría la norma y la idea de centralización. Recuérdese, en

alguna muestra como: "169. Recova. -En un documento del Rey Sabio, dado en favor de los vecinos de Murcia, se lee : "E otrosí, por fazer bien e merçet á los vezinos moradores do la cibdad e de su termino, e también é todos los del regno de Murçia, otorgamos e mandamos que non den recova en ningún lugar...” ¿Se podrá precisar el valor y etimología de esta última voz?" (RABM 15/10/1872).

30 Se citan otros diccionarios de alcance dialectal que no introducen más información que la aportada por Borao. Efectivamente, este aragonesismo se incorporará al DRAE 1925 (s. v. sargantana). 
el caso del léxico, la conocida anotación que Lapesa expresó años después acerca de que el diccionario (el académico) no debe ser solo de Madrid, sino de todo el mundo hispánico. A causa de esta doble concepción, la mayor parte de esas preguntas quedaron sin resolver y, cuando lo hicieron, se debió a que se contaba con alguna obra de consulta, como sucedía en el caso del dominio aragonés. Salvo aliva, las otras dos voces, sargantana y gurriato, se introdujeron con marca regional en el DRAE 1925. La decimoquinta edición del diccionario amplió considerablemente el número de voces de esta procedencia por la propia evolución de la dialectología o los atlas lingüísticos, con la consiguiente repercusión en la sustitución del adjetivo castellana por española (Garriga y Rodríguez 2007). Se podría plantear si la incorporación de estos contenidos en la $R A B M$ pudo influir $\mathrm{y}$, por tanto, intervenir de alguna manera en el cambio de esta concepción. Quizás parezca arriesgado afirmar este hecho con rotundidad, sin embargo, al constatar que estas voces sí están recogidas en el Fichero General de la Real Academia a través de la $R A B M$ como fuente de información, se podría pensar que, efectivamente, en algo colaboró para que se produjera ese cambio de actitud ${ }^{31}$.

Así las cosas, se podrían multiplicar los ejemplos, a pesar de que no se aportaría nada más a la descripción de este proceder en esta sección de la revista. Mayoritariamente, se trata de unidades léxicas que no estaban recogidas en los diccionarios debido a su procedencia dialectal por lo que hay que recurrir a fuentes documentales, análisis lingüístico comparativo o estudios etimológicos extranjeros para completar la información solicitada por los lectores. A pesar de ello, el repertorio lexicográfico es una fuente a la que se recurre, cuando es posible adjuntar la información requerida sobre esa palabra, como un soporte al que se le otorga cierta autoridad, sobre todo cuando es el realizado por la docta institución, aunque las remisiones que se encuentran en su interior pueden provocar la duda sobre cuál de ellas pertenece a un registro más elevado:

\section{Pregunta}

878. Panadizo. - ¿Nos podrá decir algún curioso cuál es la etimología de este nombre, cuya relación con la enfermedad que significa no puedo alcanzar, é indicarnos al mismo tiempo, ya que es sinónimo de panarizo, según el Diccionario de la Academia, cuál de estas dos voces es más culta? (RABM 30/6/1874).

31 De hecho, en el caso de aliva, los datos disponibles en el Fichero General remiten a la información publicada en la $R A B M$, a la vez que indican que es una errata y que debería leerse ativa . 
Ese valor de autoridad y de prestigio, que recaía sobre el diccionario académico principalmente, no es óbice para manifestar sus deficiencias y llegar a ponerlo en tela de juicio en muchas más ocasiones de las esperables. A partir de estas valoraciones ${ }^{32}$, se observa el comienzo de un cambio de actitud hacia el diccionario normativo a causa de que sus definiciones no resultan acertadas o todo lo correctas que deberían ser:

\begin{tabular}{|c|c|}
\hline$R A B M$ & Fuente lexicográfica \\
\hline $\begin{array}{l}\text { Sarrio. Núm. } 240 \text {, T. III, pág. } 287 .-\mathrm{La} \\
\text { palabra sarrio pertenece al diccionario } \\
\text { de la lengua castellana, y de ella } \\
\text { se ocupa el de la Academia, si bien } \\
\text { desgraciadamente no nos dice más de } \\
\text { lo que sabemos, que es un cuadrúpedo } \\
\text { llamado por otro nombre cabra montes } \\
(R A B M 15 / 10 / 1873) \text {. }\end{array}$ & $\begin{array}{l}\text { Cuadrúpedo. DAMA (DRAE 1869: s.v. } \\
\text { sarrio). }\end{array}$ \\
\hline $\begin{array}{l}\text { 365. Carlan. -Desearía tener, acerca } \\
\text { de este cargo, una noción más exacta } \\
\text { que la que me da el Diccionario de la } \\
\text { Academia al decir que es en algunas } \\
\text { partes de Aragón el que tiene cierta } \\
\text { jurisdicción y derechos en algún } \\
\text { territorio }(R A B M 31 / 5 / 1874) \text {. }\end{array}$ & $\begin{array}{l}\text {-En algunas partes de la antigua corona } \\
\text { de Aragón, el que tiene cierta jurisdicción } \\
\text { y derechos en algún territorio (DRAE } \\
\text { 1869: s.v. carlan). } \\
\text {-[...] fuera del condado de Ribagorza se } \\
\text { conocían con el nombre de castellanos. } \\
\text { La Academia dice que es }[\ldots] \text { (Borao } \\
\text { 1859: s.v. carlan) }\end{array}$ \\
\hline
\end{tabular}

32 Este proceder no era nuevo y se advirtió en Puche Lorenzo (2019b: 74) en los testimonios localizados en la prensa de la primera mitad el siglo XIX al afirmar que "[1]a autoridad y, en consecuencia, el prestigio que desprende el acceso al diccionario para el uso correcto de la lengua no es general en la prensa de la primera mitad del siglo XIX. Quienes escriben en este medio y son cercanos al estudio de la lengua, o al menos preocupados por estos asuntos, ponen de manifiesto las discrepancias existentes entre el significado de determinadas palabras en el diccionario y en la sociedad, en parte porque los significados evolucionan al compás que lo hace aquella". En el caso que ahora ocupa, se incluye el aliciente de que no estaban recogidas voces arcaicas o anticuadas, utilizadas en los documentos medievales y renacentistas.

33 En la respuesta publicada el 15 de junio de 1874 se incluye la información de este diccionario, sin citar el nombre y bajo el epígrafe de "en opinión de algunos". Se indica, igualmente, que se ha tomado como referencia la undécima edición del DRAE por ser la más cercana en el tiempo a la publicación. 


\begin{tabular}{|l|l|}
\hline Sexmo, Sexma, Sexmero. -En el & La sexta parte de cualquier cosa. \\
número 2 del tomo iii, pág. 31, se & Tómase regularmente por la de la vara. \\
preguntó la significación de las palabras & || División de territorio.|l Madero que \\
sexma y sexmero [...] El Diccionario & tiene doce dedos de ancho y doce de \\
de la Academia ha inducido en error & grueso, sin largo determinado (DRAE \\
respecto á este particular. Dice, con & 1869: s.v. sesma). \\
razón, que sesma, ó sexma, es la sexta & \\
parte de cualquier cosa. Y añade que es & \\
división de territorio, pero nada dice del & \\
tributo del seis por ciento que llevaban & \\
á veces los Reyes, y se llamó sexma, & \\
como el diez por ciento que llevaba & \\
la Iglesia se llamó décima y diezmo & \\
(RABM 30/6/1874). & \\
\hline
\end{tabular}

Las valoraciones señaladas aportan hechos objetivos sobre el proceder de las obras lexicográficas y se encuentran alentadas por la variación diatópica y diacrónica del léxico español. Por ello, ante la imposibilidad de que el diccionario académico aporte soluciones, es necesario recurrir a otras publicaciones de esa naturaleza, redactadas al margen de la Real Academia ${ }^{34}$, que arrojen luz sobre voces anticuadas o arcaicas:

\begin{tabular}{|l|}
\hline Respuesta \\
\hline 262. Alsarda. -Según el Diccionario enciclopédico de la lengua española, \\
publicado por los editores Gaspar y Roig (Madrid, 1872), la voz anticuada \\
alsarda, no incluida en el de la Academia, significa: "derecho señorial que se \\
pagaba por el aprovechamiento de las aguas [...]” (RABM 31/10/1873). \\
\hline
\end{tabular}

La mención a la obra académica a veces se encuentra plagada de ironía o expresada mediante un tono jocoso, con una clara referencia al trabajo de los académicos en determinados momentos. En esta ocasión, se introduce una valoración subjetiva, de carácter negativo, que sería ejemplo de una actitud contraria hacia la obra académica y a todo lo que representa en el plano lingüístico. Tales expresiones vienen de la mano de los lectores y raras veces de los redactores:

34 En el amplio conjunto de voces que se comentaron en esta sección, hay muchas que no tienen referencia lexicográfica alguna. Otras lo hicieron con posterioridad a esta publicación como gurriato, que se incluyó en DRAE 1899, cucharrena, en el diccionario manual de 1950, atijarero, decanía, en el DRAE 1914, boteja, fufú, en el DRAE 1925, aliala, diccionario manual de 1927, por citar solo algunos ejemplos referentes a la lexicografía académica. 


\begin{tabular}{|c|c|}
\hline$R A B M$ & Fuente lexicográfica \\
\hline $\begin{array}{l}\text { 40. Valdosa ó Baldosa. [...] no } \\
\text { hemos pedido hallar en ninguno de } \\
\text { los muchos libros de música de que } \\
\text { podemos disponer, como tampoco en } \\
\text { diferentes diccionarios, salvo el de la } \\
\text { Academia Española más moderno, que } \\
\text { nos dice que la Baldosa es un antiguo } \\
\text { instrumento músico; definición (i) } \\
\text { que nos deja con la misma boca } \\
\text { abierta que ántes teníamos, y además } \\
\text { nos pone en confusión [...] (RABM } \\
31 / 5 / 71)^{35} \text {. }\end{array}$ & $\begin{array}{l}\text { ant. Instrumento músico (DRAE 1869: } \\
\text { s.v. baldosa). }\end{array}$ \\
\hline $\begin{array}{l}\text { 364. Raso. -Según el Diccionario de } \\
\text { la Academia, Raso es una tela de seda } \\
\text { lustrosa, de más cuerpo que el tafetán } \\
\text { y menos que el terciopelo. Definición } \\
\text { luminosa que puede sacar de un } \\
\text { apuro al infeliz que necesite formarse } \\
\text { idea de la tela asi llamada. ¿Se conoce } \\
\text { el origen de esta palabra? [...] (RABM } \\
\text { 15/5/1874). }\end{array}$ & $\begin{array}{l}\text { m. Tela de seda lustrosa, de mas cuerpo } \\
\text { que el tafetán y menos que el terciopelo } \\
(D R A E 1869 \text { : s.v. raso). }\end{array}$ \\
\hline $\begin{array}{l}\text { 349. Pallique. -A propósito de esta } \\
\text { voz, dice el Diccionario de la Academia } \\
\text { que es: "La conversación de poca } \\
\text { importancia, y que debiera excusarse". } \\
\text { ¿Con que de poca importancia, eh? } \\
\text { Se conoce que los sabios académicos } \\
\text { han olvidado con los años, cómo } \\
\text { tuvieron que aguzar el ingenio en sus }\end{array}$ & $\begin{array}{l}\text { m. fam. La conversación de poca } \\
\text { importancia, y que pudiera ó debiera } \\
\text { excusarse. Inutilis confabulatio (DRAE } \\
\text { 1832: s.v. palique) })^{36} \text {. }\end{array}$ \\
\hline
\end{tabular}

35 Es uno de los pocos casos en los que, tras poner en entredicho la labor académica, se genera una defensa del diccionario en la respuesta de los redactores. Sin embargo, el 15 de agosto de ese mismo año se publicó otra respuesta, firmada por Barbieri, en la que se indicaban los errores de las correspondencias latinas de los instrumentos musicales.

36 A partir de esta edición se suprimió que pudiera o debiera excusarse, de modo que el lector tendría a la mano una edición antigua del diccionario académico. 
mocedades para dar palique á las mamas ó á las niñas, según que convenia usar de los fuegos curvos ó rectos para rendir la plaza. No me conformo, pues, con semejante definición, y creo que el palique es algo más de lo que dice la Academia. ¿Me lo negará alguno? (RABM 30/4/1874).

Por otra parte, los lectores no escapan a las curiosidades que suscita el reciente vocabulario especializado, procedente del avance de las ciencias y de las técnicas que experimentaron un auge sobresaliente durante el siglo XIX. Esto se tradujo en un aumento considerable del léxico y la incorporación de neologismos de forma y de sentido (Garriga Escribano y Rodríguez 2011). Estas nuevas palabras generan dudas por su origen y son objeto de propuestas alternativas por parte de los lectores que, como se verá, parece que irían en consonancia con las directrices adoptadas por la Academia con respecto al léxico especializado años después:

\begin{tabular}{|c|c|}
\hline$R A B M$ & Fuentes lexicográficas \\
\hline $\begin{array}{l}\text { 413. Fotolitozincografía.- ¿Puede } \\
\text { sustituirse, cual se hace en Francia, } \\
\text { este nombre harto largo, por el de } \\
\text { fototipografía, cuando el nuevo } \\
\text { procedimiento se aplicaála reproducción } \\
\text { de los caracteres tipográficos? ( } R A B M \\
15 / 10 / 1874) \text {. }\end{array}$ & $\begin{array}{l}\text { f. Arte de obtener por medio de la } \\
\text { fotografía clisés tipográficos }(D R A E \\
\text { 1899: s.v. fototipografía })^{37}\end{array}$ \\
\hline $\begin{array}{l}\text { 446. Túnel.- Esta palabra ¿se usa tan } \\
\text { solo desde que se designó con ella } \\
\text { la famosa via subfluvial de Lóndres, } \\
\text { ó tiene origen más antiguo? Si es } \\
\text { moderna su invención, ¿á qué causa se } \\
\text { debe haberla adoptado? [...] ( } R A B M \\
\text { 20/3/1875). }\end{array}$ & $\begin{array}{l}\text { m. Trozo de camino subterráneo en los } \\
\text { ferrocarriles. Suele aplicarse también al } \\
\text { camino abierto debajo de un rio. Es voz } \\
\text { de uso reciente ( } D R A E \text { 1869: s.v. túnel). }\end{array}$ \\
\hline
\end{tabular}

37 Fotolitozincografia nunca llegó a formar parte de las páginas de un diccionario, mientras que la propuesta del lector sí lo hizo en años siguientes, por eso se ha incluido la referencia de fototipografía. Es interesante plantearse hasta qué punto estas propuestas influyeron en el devenir de estos repertorios lexicográficos. 
La atención que despertaba el léxico especializado iba dirigida no solo al de procedencia científica o técnica, sino también al vinculado a la profesión que desempeñaban los potenciales lectores de la revista. En un principio, todo parece indicar que estas cuestiones serían resueltas con presteza, pero no fue así y dichos interrogantes quedaron sin responder en los números siguientes:

\section{Preguntas sin respuesta}

871. Indizar ó Indicear ${ }^{38}$.- ¿Se podría enriquecer nuestra lengua con el verbo indizar en significacion de hacer índices? De ser admisible el neologismo propuesto, ¿sería más eufónico pronunciarle indicear, con lo que se conseguiría hacerle verbo regular? Hacemos tal pregunta porque hoy dia es esta palabra objeto de trabajos filológicos en Méjico, donde parece se ocupan con más interés que nosotros de la rica fabla castellana ( $R A B M 15 / 6 / 1874)$.

376. Archivo y Biblioteca.- ¿Puede establecerse facultativamente una línea divisoria que establezca dónde acaba el archivo y comienza la biblioteca?

\subsection{LA RABM EN EL DESARROLLO DE LA CIENCIA FILOLÓGICA}

El siglo XIX estuvo marcado por el nacimiento de la filología comparada al tener conocimiento del sánscrito y poder establecer el parentesco entre diferentes lenguas. Ese estudio comparado de las lenguas dio lugar, en la segunda mitad del siglo, al estudio histórico, pues no se podía concebir la lingüística sin ese factor. En este sentido, la $R A B M$, desde sus páginas intentó intervenir en el avance de la nueva disciplina, ampliamente cultivada en Alemania o Francia. De ahí que se hiciera eco de determinadas propuestas, que no llegaron a materializarse nunca, como fue el caso de la redacción de una gramática comparada:

Se ha propuesto á la Real Academia Española por varios de sus individuos de número, entre ellos los Sres. Canalejas, Fernandez-Guerra, y Valera, que por aquel Cuerpo literario se redacte y publique una gramática comparada de las lenguas neo-latinas, habladas y escritas en la

38 El neologismo indizar se incorporó al DRAE 1984, casi cien años después de que se formulara la pregunta que se adjunta. No se ha encontrado testimonio de ella en los corpus académicos (CORDE y CDH), aunque, como se ha constatado, se utilizaba con frecuencia en el siglo XIX, sobre todo en el último tercio, y un primer ejemplo temprano se encuentra en 1846 dentro del Tratado de medicina y cirugía legal, tomo II, de Pedro Mata, página 409. Resulta interesante la apreciación realizada sobre el tratamiento de la lengua a ambos lados del océano. 
Península. Aplaudimos el pensamiento y celebraremos llegue á realizarse (RABM 30/11/1871: 296).

Pero sus páginas se convirtieron en el lugar idóneo para difundir las novedades bibliográficas, como la publicación de recientes gramáticas de las lenguas teutonas ${ }^{39}$ o de la árabe ${ }^{40}$, tanto en España como en el extranjero. De este modo, quedaba patente que los principales avances en materia lingüística se llevaban a cabo más allá de nuestras fronteras, aunque eso no impedía que fueran conocidos por los estudiosos del país. Así las cosas, se dio publicidad a la aparición, en París, del primer número de la revista Romania, en 1872, que continúa vigente en la actualidad ${ }^{41}$. El avance de los estudios filológicos en Europa era imparable y no solo en Francia, sino también en Italia, surgieron las primeras publicaciones periódicas dedicadas a estos conocimientos. Sin embargo, Alemania iba a la cabeza en cuanto al impulso que recibía este tipo de estudios, pues en el año 1872 se publicaron 4316 obras de las que 301 pertenecían al ámbito de la filología ( $R A B M$ 31/10/1872: 317). La $R A B M$ se convirtió en el vehículo de transmisión de conocimientos novedosos que permitieron su desarrollo en el ámbito peninsular tanto por las fechas tempranas de su publicación, frente a otros títulos que vieron la luz después, como por el potencial lector al que iban destinados.

Dentro de esas revisiones bibliográficas, mostradas con espíritu crítico, se incluían también obras especializadas en las que estaba patente, de forma más o menos directa, el tratamiento de la lengua y, concretamente, del léxico. Dentro de esta línea se inscribe la reseña realizada a la obra de Picatoste, $E l$ tecnicismo matemático en el Diccionario de la Academia Española, del que alaba el tono adoptado a la hora de censurar el diccionario de la institución académica en virtud del tratamiento otorgado al léxico de esa disciplina:

39 La noticia va destinada a los filólogos, como se advierte en "A los que entre nosotros cultivan los estudios filológicos, puede interesarles la siguiente nota bibliográfica: $A$ comparative Grammar of the teutonic languages, being at the same time a historical grammar of the english language, by James Helfenstein. Ph. D. London, Macmillan, 1871, in 8, precio 30 francos" (RABM 15/12/1871: 312).

40 Es el caso de la Gramática de la Lengua Arábiga publicada por José Moreno Nieto en 1872. El autor de la reseña, José María Escudero de la Peña, se lamenta del poco interés que ha recibido el elemento árabe dentro de los estudios históricos y lingüísticos, hasta entonces. La causa que podría justificar esa situación sería el abandono que padecía la enseñanza de esa lengua en los planes de estudio españoles (RABM 31/1/72: 23).

${ }^{41}$ A partir de esta reseña se pone en conocimiento que, hasta la fecha, solo se conocían dos revistas de esas características en España: Jahrbuch für romanische und englische Literatur y la Revue des langues romanes. En España, hubo que esperar a 1914, año en que se comenzó a publicar la Revista de Filología Española. 
[H]a sabido hermanar en el opúsculo de que tratamos la ligera censura que, en lo relativo al tecnicismo matemático, hace del Diccionario de la Academia, con la forma cortés y templada, "huyendo, dice, de ensañarse con aquella Corporación, ó con sus trabajos á lo menos, y de escribir con pretensiones y con aire dogmático, rechazando así tal vez la especie de tiranía con que por algún tiempo se quisieron imponer en la enseñanza las doctrinas y los libros de la Academia" (RABM 15/10/1873: 301).

No será este el único caso, pues se citarán obras del campo de la psicología ${ }^{42}$ o del ámbito militar. A este último se adscribe la reseña que se publicó sobre el Diccionario militar etimológico, histórico, tecnológico, con dos vocabularios francés y alemán de José Almirante, editado en 1869. En el caso de Picatoste, se consideraban adecuados la crítica y el tono adoptado para formularla; mientras que, ahora, aunque se reconoce el beneplácito que otorgó la Academia al autor, no se considera que esté bien confeccionada desde un punto de vista filológico. Una vez más, se percibe una actitud hacia la Academia y sus obras, representantes de la norma del español, por parte de los redactores que está en plena consonancia con el carácter innovador de la revista. Como se mostrará a continuación y se ha podido constatar en epígrafes anteriores, a pesar de no expresarse directamente esa actitud, sí está latente en el modo de proceder y en el pensamiento de los redactores, conformando lo que podría ser una ideología oculta ${ }^{43}$ :

Juzgado ya ventajosamente este libro por las Academias Española y de la Historia, cuyos informes aparecen en sus primeras páginas, y aceptado por el público como obra maestra, de instructiva lectura, de erudición no escasa, severa critica y galana frase [...], no mostrándose extraño a los estudios filológicos, en la parte etimológica, en la cual, si bien no resuelve muchas veces las cuestiones dudosas, aduce en cambio profusión do citas y opiniones, y prueba siempre que le son familiares estos conocimientos (RABM 30/6/1874: 187).

42 Se insiste, en este caso, en el hecho de que para abordar o teorizar sobre una materia hay que dominar el léxico técnico que la caracteriza: "El primer paso que debe darse para aprender una ciencia, es conocer su tecnicismo, tanto más difícil y abstruso cuanto más aquella se aparte de los conocimientos vulgares. [...] A este género pertenecen sin duda la Psicología y las ciencias que con ella más íntimamente se relacionan, hoy dadas al olvido y cultivadas tan sólo por algunos seres excéntricos, al decir de las gentes, que tienen la manía de dedicarse á altas filosofías" (RABM 31/1/1874: 27).

43 Sin entrar en el desarrollo de las ideologías de la lengua, cuyos planteamientos generales pueden leerse en Arnaux y del Valle (2010) ni las controversias que hayan podido generar algunos autores, sí se puede afirmar que existe esa ideología oculta palpable a través de la elección del código, en los registros y los estilos del habla (Puche Lorenzo en prensa). 
Además de este tipo de aportaciones, donde se conjuga el historicismo de la etimología y el interés por el vocabulario técnico cuya repercusión se hizo notar en las ediciones del diccionario académico durante el siglo XIX (Clavería 2016), la revista incluye otro género de artículos, más cercanos a la investigación, que constituirían el germen del rumbo que tomaría la publicación en épocas posteriores, sobre todo en el tercer periodo, considerado como la época dorada de este título. En ellos se combina el componente histórico con el lingüístico o asumen este último eje con exclusividad. A través de colaboraciones de esa enjundia se recopilaron, por ejemplo, los nombres de las celebraciones que practicaban los árabes, como atahor, leila, açalá, etc., mediante la consulta de documentos inquisitoriales ${ }^{44}$. Algunas de ellas, continuaron produciéndose hasta la desaparición de los vestigios del reino nazarí (González Sopeña 2019). En dos entregas, Sbarbi editó su Un plato de garrafales (Juicio crítico a Pepita Jiménez, por D. J. V.) ${ }^{45}$ donde revisa la obra de Valera, bajo la óptica de la pureza del idioma y el ataque al galicismo. El tono irónico que sustenta el trabajo se ve favorecido por el paralelismo y la imagen que le sugiere la comida, como ha analizado en profundidad Provencio Garrigós (en prensa).

Aparecen, de forma novedosa, recopilaciones cuantitativas de determinados usos lingüísticos en obras literarias, sin que se exprese una justificación o valoración cualitativa de ese recuento. Este tipo de recuento y búsqueda de concordancias constituye un adelanto en el tiempo considerable frente a una metodología de estudio, centrada en la estadística, que se expandió a finales del siglo XX. En este caso, se desconoce el nombre del autor, que firma como "Un apasionado de Cervantes" y del que se dice:

Un anciano y docto eclesiástico, residente en una población de Castilla la Vieja, tiene escrito de su letra, muchos años há, un Diccionario con el titulo de Concordancias del Quijote, obra en que se incluyen todas las voces usadas por Cervantes en El Ingenioso Hidalgo, designando el capitulo, página y linea donde aparecen. De este mismo respetabilísimo Señor Sacerdote es la nota siguiente, que puede servir como de muestra de su laboriosidad incansable (RABM 31/1/1875: 28).

Dedica su esfuerzo a contar las veces que se han usado los adverbios quizá y quizás en las obras de autores clásicos publicadas por la imprenta de

44 Fue publicado por Gredilla bajo el título de "Cerimonias de moros que hacen los moriscos" (RABM 15/6/1874: 165-168).

45 Así se contiene en RABM 30/6/1874: 188-190 y 15/7/1874: 204-206. Con posterioridad, se hizo referencia a esta crítica en El Averiguador Universal, periódico que dirigía. 
Rivadeneyra. En un número posterior de la revista, volvió a aparecer la colaboración de este "clérigo anónimo" sobre las locuciones adverbiales por lo menos, a lo menos, al menos, a menos de y a menos que (RABM 20/6/1875: 202). Quizás este tipo de aportaciones no hubieran visto la luz a no ser por la aparición de este nuevo medio escrito.

El 5 de julio de 1877 se inauguraba el número con el más extenso artículo de naturaleza lingüística publicado en las dos etapas iniciales de la revista. Ocupa cinco páginas y, con el título de Límites de las lenguas románicas, Milá y Fontanals ${ }^{46}$ planteó una cuestión que no ha perdido actualidad. La publicación del Étude sur la limite géographique de la langue dıoc et de la langue droil de Tourtoulon y Bringuier le lleva a plantear la pregunta que estaba en boga entre los filólogos del momento: “¿En los confines de dos lenguas de una misma familia, se pasa repentinamente de una á otra, ó bien hay una transición graduada debida á la fusión de las dos lenguas?" ( $R A B M$ 5/7/1877: 196-200). Como era esperable, intenta responder a ese interrogante a partir de los límites de las lenguas de oc y de oil, como una posible reseña de la obra. Sin embargo, desplaza ese asunto a la frontera entre catalán y castellano porque:

Creemos que un estudio de los límites de la lengua castellana y castellanoaragonesa y de la catalana (en que comprendemos la de Valencia), daría resultados más claros y todavía menos favorables á la teoría de la fusión, ya porque las dos lenguas son de índole más diversa que las de oc y oil, ya porque ofrecen más homogeneidad interior (sin que por esto deje de haber variedades), ya porque acaso el catalán se mantiene algo más entero que los dialectos del Mediodía de Francia.

De hecho, como argumento en contra de ese cambio gradual manifiesta que el catalán de Barcelona se encuentra más castellanizado que el de los pueblos fronterizos con tierras aragonesas. No obstante, muestra especial atención a los límites de la provincia de Alicante, fronterizos con Murcia y La Mancha, donde los cambios de lengua son repentinos, aunque eso no impide la constatación de interferencias fonéticas o léxicas. Tras el desarrollo de su exposición, matizará sus palabras para señalar que sí existe graduación fonética entre el catalán y el castellano y que es más frecuente la castellanización que la catalanización. En tiempos más cercanos, se ha comprobado cómo el cambio de lengua en zonas fronterizas se encuentra

46 Este estudio se integró dentro de las Obras completas de Milá y Fontanals, publicadas por Menéndez Pelayo en 1895. Este puede hallarse en el tomo VI, pp. 530-536, como apéndice puesto que el recopilador olvidó incluirlo en el volumen anterior. 
justificado por razones socio-históricas complejas y de gran interés (Abad Merino 1994). El texto se concibe en un momento en el que comienzan los estudios dialectológicos, que no cristalizarían en un proceso científico hasta la pulicación de El dialecto leonés, en 1906, por Menéndez Pidal (Gimeno 2003: 70). Así las cosas, se introduce una novedad consistente en el interés por las fronteras lingüísticas que, en el caso del catalán, serían abordadas después por Griera, en relación con el aragonés, y en la segunda mitad del siglo XX, principalmente, las correspondientes con el castellano (Sinner y Wesch 2008). Además de la innovación que supuso en su momento abordar estas cuestiones, podría ser este trabajo ejemplo del germen de lo que después fue la Escuela de filología española, pues Milán y Fontanals fue maestro de Menéndez Pelayo y este, a su vez, de Menéndez Pidal.

\section{CONCLUSIONES}

A través de estas páginas, se ha pretendido describir una publicación periódica que comenzó a editarse en el último tercio del siglo XIX y continuó haciéndolo durante buena parte del siglo XX. Considerada como uno de los principales vehículos de esta naturaleza para la difusión de la cultura española, era necesario constatar qué actuación se procuró desde aquella hacia el avance de la lingüística diacrónica o el uso de la lengua española en el siglo XIX. Para ello, se ha partido de su consideración como texto efímero, que se integra en el conjunto de la prensa especializada y, a pesar de que la distinción entre revista y periódico no era suficientemente clara en el periodo acotado, en virtud de sus características y del título con el que fue bautizada, reúne los requisitos indispensables para ser clasificada tipológicamente como revista, a pesar de que esa distinción terminológica no fuera efectiva hasta el siglo siguiente. Por ello, podría decirse que, sin ánimo de perdurar en el tiempo por su naturaleza editorial, sí disponía de un interés de intervenir en determinados asuntos culturales y en difundir o comunicar el conocimiento surgido en determinados ámbitos.

En los números correspondientes a los dos primeros periodos, editados en su totalidad durante el siglo XIX, se ha detallado el inmenso interés que posee la documentación antigua, promovida por el fin que persigue la revista y la relación emisor/destinatario, por una parte, y por otra, el contexto cultural del momento caracterizado por un marcado historicismo. Este hecho justifica, igualmente, el afán por difundir desde sus páginas aquellos estudios foráneos fundamentados en el seno de la filología comparada y la 
lingüística histórica, junto a otros, publicados por autores nacionales, que con mayor o menor acierto intentaban colaborar al conocimiento diacrónico del idioma. Existe, por tanto, un intento de sacar a España del atraso en que se encontraba frente a otros países europeos.

En los números que conforman el corpus de trabajo, se ha encontrado una sección en la revista sobre preguntas y respuestas, que desapareció posteriormente. A partir de ella, se ha detectado una preocupación especial por la etimología, el origen y el significado de las palabras, materializada mediante un proceso interactivo en el que la revista actúa de soporte. Además de su importancia para conocer mejor el pasado lingüístico, se desvelan determinadas actitudes e ideologías por parte de los lectores que se alejan de la norma, representada, en esta ocasión, por el diccionario académico. En él se pudo intervenir, entendido como interceder o tomar parte en ese asunto, para que, en ediciones posteriores, se introdujeran algunas de las voces aquí propuestas, como se ha comprobado a través del Fichero General académico. Aunque también está presente la corrección idiomática, motivada por las numerosas preguntas de carácter ortográfico. Actitudes estas, corrección y alejamiento de la norma en léxico y ortografía, principalmente, que reflejan el sentir de la sociedad decimonónica, al menos de la que gozaba de un alto nivel cultural.

Finalmente, solo queda incidir en la importancia que adquiere la prensa para conocer la lengua del siglo XIX. Sus páginas proporcionan datos relevantes y reveladores sobre la concepción y el uso del idioma, de hecho, Echegaray consideró que "el periodismo, en la trama de las sociedades, es como el sistema nervioso por donde circulan las ideas".

\section{REFERENCIAS BIBLIOGRÁFICAS}

Abad Merino, mercedes. 1994. El cambio de lengua en Orihuela, estudio socioligüísticohistórico del siglo XVII. Murcia: Caja Rural Central.

En prensa. Percepción de la diversidad dialectal murciana y prejuicios lingüísticos en un artículo costumbrista del siglo XIX español. En Carmen Marimón, Wim Remysen y Fabio Rossi (dir.). Les idéologies linguistiques: débats, purismes et stratégies discursives, pp. 25-46. Berlín: Peter Lang.

Alvar Ezquerra, Manuel. 1983. Los prólogos del Diccionario académico. Nomenclatura específica y microestructura, Revista de Filología Española LXIII 3/4: 205-222.

Amores, Montserrat y Beatriz Ferrus (eds.). 2017. La España Moderna (1889-1914). Aproximaciones literarias y lingüísticas a una revista cultural. Madrid: Iberoamericana.

ARNAUX, ElVIRA NARVAJA DE. 2019. La prensa escrita en manuales de retórica del siglo XIX: deslindes genéricos e ideologías lingüísticas. Olivar 19: 1-19. 
Arnoux, Elvira Narvaja de y José del Valle. 2010. Las representaciones ideológicas del lenguaje. Discurso glotopolítico y panhispanismo, Spanish in Context 7:1: 1-24.

Barrera, Carlos (ed.). 2000. El periodismo español en su historia. Barcelona: Ariel Practicum.

Bastardín Candón, Teresa. 2020. Creencias y actitudes lingüísticas sobre las hablas andaluzas en la prensa de mediados del siglo XIX. Boletín de Filología LV 2: 285-310.

Borao, Jerónimo. 1859. Diccionario de voces aragonesas. Zaragoza: Imprenta y Librería de D. Calisto Ariño.

BuzeK, Ivo y MoniKa ŠInková (eds.). 2015a. Una cercana diacronía opaca: Estudios sobre el español del siglo XIX. Études Romanes de Brno 36(1).

(eds.). 2015b. Una cercana diacronía opaca: Estudios sobre el español del siglo XIX. Études Romanes de Brno 36(2).

CABrÉ, M. ${ }^{a}$ Teresa. 2006. Lenguajes de especialidad y enseñanza de lenguas. En M. ${ }^{a}$ Teresa Cabré y Josefa Gómez de Enterría. La enseñanza de los lenguajes de especialidad. La simulación global, pp. 9-73. Madrid: Gredos.

Calvi, Maria Vittoria. ${ }^{82019}$. Las lenguas de especialidad. En Maria Vittoria Calvi, Cristina Bordonaba, Giovanna Mapelli, Javier Santos López (eds.). Las lenguas de especialidad en español, pp. 15-54. Roma: Carocci editore.

Carpi, Elena y Rosa M. García JimÉnez (eds.). 2017. Herencia e innovación en el español del siglo XIX. Pisa: University Press.

Carriazo Ruiz, José Ramón. 2017. Diccionarios etimológicos, Estudios de Lingüística del Español 38: 7-33.

Clavería Nadal, Gloria. 2016. De vacunar a dictaminar: la lexicografía académica decimonónica y el neologismo. Madrid: Iberoamericana/ Vervuert.

Conde de la ViÑAZA, El. 1893. Biblioteca histórica de la filología castellana, tomo tercero. Madrid: Imprenta y Fundición de Manuel Tello.

Esteve Serrano, Abraham. 1982. Estudios de teoría ortográfica del español. Murcia: Universidad de Murcia.

Fuentes Aragonés, Juan Francisco y Javier Fernández Sebastián. 1997. Historia del periodismo español: prensa, política y opinión pública en la España contemporánea. Madrid: Síntesis.

Garriga Escribano, Cecilio y Francesc Rodríguez. 2007. 1925-1927 del "Diccionario usual" y del "Diccionario manual". Boletín de la Real Academia Española 87 (296): 239-317.

2011. Lengua, ciencia y técnica. En Manuel Silva (dir.). Técnica e ingeniería en España VI. El ochocientos: De los lenguajes al patrimonio, pp. 81-120. Zaragoza: Institución Fernando "el Católico".

Gimeno MenÉNDEZ, Francisco. 2003. Historia de la dialectología y sociolingüística españolas. En Carmen Alemany et alii (coords.). Actas del Congreso Internacional "La lengua, la Academica, lo Popular, los Clásicos, los Contemporáneos”, pp. 67-84. Alicante: Universidad de Alicante.

GonzÁlez SopeÑa, InMaculada. 2019. Vida social en el reino de Granada a través de sus arabismos (1491-1621): "alguadoc", "azalá", "leila", "macaber". Revista de Investigación Lingüistica 22: 29:313.

López Serena, Araceli, Del Rey Quesada, Santiago y Elena Carmona Yanes (eds.). 2020. Tradiciones discursivas y tradiciones idiomáticas en la historia del español moderno. Berlín: Peter Lang.

Magallón, Félix, Navarro, Vicente y Federico Navarro. 1959. Índice de la Revista de Archivos, Bibliotecas y Museos (1871-1957). Madrid: Tipografía Moderna. 
Marimón Llorca, Carmen e Isabel Santamaría Pérez (eds.). 2019. Ideologías sobre la lengua y medios de comunicación escritos. El caso del español. Berlín: Peter Lang.

Martínez EgIDo, José JoAquín. 2019. Lo académico como argumento de autoridad: perspectiva ideológica de los columnistas ante la norma académica. En Carmen Marimón Llorca e Isabel Santamaría Pérez (eds.). pp. 175-192.

Melis, Chantal y Marcela Flores (eds.). 2015. El siglo XIX. Inicio de la tercera etapa evolutiva del español. México: UNAM, Instituto de Investigaciones Filológicas.

Menéndez Pidal, Ramón. 1961. Las leyes fonéticas, su esencia histórica. Estudios de lingüistica (Las leyes fonéticas, Menendus, El diccionario ideal, y otros), pp. 11-32. Madrid: Espasa-Calpe.

Ossorio y Bernard, MANuel. 1903. Ensayo de un catálogo de periodistas españoles del siglo XIX. Madrid: Imprenta y litografía de J. Palacios.

Provencio Garrigós, Herminia. 2019. Escrituras e impresos efímeros del siglo XIX: espacios en el continuum diacrónico de la lengua. Anuari de Filologia. Estudis de Lingüistica 9: 59: 90.

En prensa. Desafíos a la ideología lingüística estándar del siglo XIX en El Averiguador Universal (1879-1882). En Carmen Marimón, Wim Remysen y Fabio Rossi (dir.), Les idéologies linguistiques: débats, purismes et stratégies discursives, pp. 159-180. Berlín: Peter Lang.

Puche Lorenzo, Miguel Ángel. 2002. Los diccionarios etimológicos en el siglo XIX, de Roque Barcia a Eduardo de Echegaray. En Mar Campos Souto y José Ignacio Pérez Pascual (coords.). De historia de la lexicografía, pp. 181-191. La Coruña: Toxosoutos.

2019a. La utilidad de lo efímero en el estudio de la lengua del s. XIX: cuestiones gramaticales a través de la prensa. Anuari de Filologia. Estudis de Lingüistica 9: 179-202.

2019b. El DRAE (1817-1842) a través de la prensa española. ELUA, Anexo V: 65-88.

En prensa. Sobre El Averiguador y la lengua. La ideología lingüística en la prensa del siglo XIX. En Carmen Marimón, Wim Remysen y Fabio Rossi (dir.), Les idéologies linguistiques: débats, purismes et stratégies discursives, pp. 139-158. Berlín: Peter Lang.

Ramírez Luengo, José Luis (ed.). 2012. Por sendas ignoradas. Estudios sobre la lengua española en el siglo XIX. Lugo: Axac.

Real Academia Española. En línea. Nuevo Tesoro Lexicográfico de la Legua Española. Disponible en http://ntlle.rae.es/ntlle/SrvltGUIMenuNtlle? $\mathrm{cmd}=$ Lema\&sec=1.2.0.0.0. [Consulta 10/09/2020].

En línea. Fichero General. Disponible en https://webfrl.rae.es/fichero.html. [Consulta $10 / 09 / 2020]$.

Rivas Zancarrón, Manuel y Victoriano Gaviño RodríGuez (coords.). 2020. Creencias y actitudes ante la lengua en España y América (siglos XVIII y XIX). Madrid: Iberoamericana.

RODRíGUEZ-TAPIA, SERGIO. 2016. Los textos especializados, semiespecializados y divulgativos: una propuesta de análisis cualitativo y de clasificación cuantitativa. Revista Signa 25: 987-1006.

RoNDA IgLeSIAS, JAVIER y José LuIS AlCAIDE. 2010. El periodismo especializado. El gran reto del periodista. En Ramón Reig (coord.). La dinámica periodística: perspectiva, contexto, métodos y técnicas, pp. 147-159. Sevilla: Asociación Universitaria Comunicación y Cultura.

SÁnchez-Prieto Borja, Pedro. 2011. La edición de textos españoles medievales y clásicos. Criterios de presentación gráfica. San Millán de la Cogolla: Cilengua.

SBARBI, José MARÍA. 1891. Monografia sobre los refranes, adagios y proverbios castellanos y las obras ó fragmentos que expresamente tratan de ellos en nuestra lengua. Madrid: Imprenta y Litografía de los Huérfanos.

SeOAne, M. ${ }^{a}$ Cruz. 1983. Historia del periodismo en España. II: El siglo XIX. Madrid: Alianza. 
Sinner, CARSten y ANDREAS Wesch. 2008. El castellano en las tierras de habla catalana. Madrid: Iberoamericana/ Vervuert.

Štrbáková, RADANA. 2013. La dinámica del léxico de la moda en el siglo XIX: estudio de neología léxica. Bucureşti: Editura Universităţii din Bucureşti.

Zamorano Aguilar, Alfonso (ed. y coord.). 2012. Reflexión lingüistica y lengua en la España del XIX. Marcos, panoramas y nuevas aportaciones. Muenchen Limcom Studies in Romance Linguistics. 